\title{
SULPHUR HEXAFLUORIDE IN THE TREATMENT OF FLAT ANTERIOR CHAMBER FOLLOWING TRABECULECTOMY
}

\author{
BIJAN BEIGI ${ }^{1}$, MICHAEL O'KEEFE ${ }^{2}$, KAIS ALGAWI ${ }^{2}$, ROBERT ACHESON $^{2}$ and \\ JOHN BURKE ${ }^{3}$ \\ London, Dublin, Ireland and Sheffield
}

\begin{abstract}
SUMMARY
The efficacy and side effects of sulphur hexafluoride $\left(\mathrm{SF}_{6}\right)$ in the reformation of the flat anterior chamber (AC) after standard trabeculectomies were studied. Ten patients with lenticulocorneal touch following trabeculectomy were enrolled. All had water-tight conjunctival wounds with overflowing fistulas. In 5, one to four surgical attempts to reform the $\mathrm{AC}$ were unsuccessful. Two to seven days after trabeculectomy, the $\mathrm{AC}$ was reformed by a single injection of $\mathrm{SF}_{6} /$ air mixture (20-40\%). Gas was injected through the limbus at 3 or 9 o'clock. The $\mathrm{AC}$ remained deep after absorption of the gas in 2-7 days. All patients had stromal oedema in the first 4 days. This resolved and specular microscopy did not show any abnormality. After a mean follow-up of 2.5 years, all had normal intraocular pressure, 3 with one topical antiglaucoma treatment. Three patients developed cataracts before and 3 after reformation of the AC. The latter 3 were not anterior capsular cataracts as induced by gases. $\mathrm{SF}_{6} /$ air mixture $(20-40 \%)$ is inert and kind to the cornea and, as it is absorbed in less than 7 days, it exerts minimal damage to the crystalline lens. It is effective in the reformation of flat ACs.
\end{abstract}

Flat anterior chamber (AC) with hypotony is a serious complication of drainage surgery, with an incidence of $2-4 \%{ }^{1}$. This can be reduced further with new surgical precautions such as releasable sutures. Flat $\mathrm{AC}$ is due either to a leaking conjunctival wound or to an over-filtering fistula. If untreated, it may cause corneal endothelial and stromal damage, peripheral anterior synaechiae, closure of filtering

From: ${ }^{1}$ Adnexal Service, Moorfields Eye Hospital, London, UK; ${ }^{2}$ Department of Ophthalmology, Mater Misericordiae Hospital, University College Dublin, Ireland; ${ }^{3}$ Department of Ophthalmology, Royal Hallamshire Hospital, Sheffield, UK.

Correspondence to: Mr Michael O'Keefe, FRCS, FRCOphth, Department of Ophthalmology, University College Dublin, Mater Misericordiae Hospital, Eccles Street, Dublin 7, Ireland. fistula and cataract. ${ }^{2}$ Hypotonic maculopathy and serous retinal detachment are other possible complications.

A leaking conjunctival wound can be dealt with either conservatively, by padding, insertion of a contact lens and scleral shell, ${ }^{2-4}$ or by surgical intervention. When flat $\mathrm{AC}$ is due to an overflowing fistula, suturing of the scleral flap, autogenous subconjunctival blood patch or injection of air into the AC with drainage of supra-choroidal fluid have been suggested. ${ }^{5,6}$ Intraocular injection of perfluoropropane $\left(\mathrm{C}_{3} \mathrm{~F}_{8}\right)$ without a drainage sclerotomy has also been successfully employed in pseudophakics. ${ }^{7,8}$

Surgeons have been reluctant to utilise gases in the AC because of their potential side-effects. ${ }^{9}$ The aim of this study was to examine the efficacy and sideeffects of sulphur hexafluoride $\left(\mathrm{SF}_{6}\right)$ gas/air mixture $20-40 \%$ in reforming the AC.

\section{PATIENTS AND METHOD}

Between July 1989 and January 1994, all consecutive patients with flat ACs following 490 standard Cairnstype trabeculectomies ${ }^{10}$ were evaluated. Cases with a leaking conjunctival wound and those responding to conservative treatment were excluded.

Ten patients ( 6 men and 4 women) met the study criteria. Their ages ranged from 59 to 84 years (mean 68 years). They were followed up from 6 months to 5 years (mean 2.5 years). In 9 patients the $\mathrm{AC}$ was flat on the first post-operative day. In case 6 , the AC was formed on the first day but flat on the second day. All had choroidal detachment and lenticulocorneal touch due to an overflowing fistula. Initial conservative treatment with double padding, pupil dilation and topical steroid was unsuccessful. In 5 patients (cases 2, 3, 6, 7,9) surgical attempts (one to four) to reform the AC using Balanced Salt solution 
Table I. Ocular findings and surgery before reformation of the anterior chamber (AC)

\begin{tabular}{|c|c|c|c|c|c|}
\hline Patient no. & Age/Sex & Ocular history & Pre-operative VA & First surgery/further attempts & $\begin{array}{l}\text { Post-operative VA } \\
\text { with flat AC }\end{array}$ \\
\hline 1 & 79/M & POAG & $6 / 18$ & Trabeculectomy & $6 / 24$ \\
\hline 2 & $62 / \mathrm{M}$ & CACG & $6 / 5$ & Trabeculectomy/conjunctival resuturing & $6 / 18$ \\
\hline 3 & $61 / \mathrm{M}$ & POAG & $6 / 12$ & Trabeculectomy/air injection & $6 / 12$ \\
\hline 4 & $67 / \mathrm{F}$ & CACG, Cat.+++ & $\mathrm{CF}$ & Trabeculectomy & $\mathrm{CF}$ \\
\hline 5 & $72 / \mathrm{F}$ & AACG, Cat.++ & $6 / 60$ & Trabeculectomy & $6 / 60$ \\
\hline 6 & $65 / \mathrm{M}$ & PXF (advanced) & $\mathrm{HM}$ & Trabeculectomy/Na hyaluronate injection & $\mathrm{HM}$ \\
\hline 7 & $67 / F$ & POAG & $6 / 6$ & $\begin{array}{l}\text { Trabeculectomy } / 2 \text { resuturing of flap/ } 4 \\
\text { reformation attempts by BSS }+\mathrm{Na} \\
\text { hyaluronate }\end{array}$ & $4 / 60$ \\
\hline 8 & $84 / \mathrm{F}$ & PXF & $6 / 18$ & Trabeculectomy & $6 / 60$ \\
\hline 9 & $68 / \mathrm{M}$ & PXF, Cat.+ & $6 / 6$ & $\begin{array}{l}\text { Trabeculectomy/resuturing of flap/ } \mathrm{Na} \\
\text { hyaluronate injection }\end{array}$ & $5 / 60$ \\
\hline 10 & $59 / \mathrm{M}$ & CACG & $6 / 6$ & Trabeculectomy & $6 / 6$ \\
\hline
\end{tabular}

VA, visual acuity; POAG, primary open-angle glaucoma; CACG, chronic angle-closure glaucoma; AACG, acute angle-closure glaucoma; PXF, pseudoexfoliation glaucoma; Cat., cataract.

(BSS), sodium hyaluronate, air and resuturing of the scleral flap were ineffective (Table I).

Two to seven days after trabeculectomy the ACs were reformed by injecting $\mathrm{SF}_{6} /$ air mixture, in 6 cases under topical anaesthesia. Snellen visual acuity, intraocular pressure, crystalline lens and fundus were assessed pre- and post-operatively.

The $\mathrm{SF}_{6}$ concentration in the mixture was $40 \%$ in 4 and $20 \%$ in 6 patients. $\mathrm{SF}_{6}$ was drawn up into a syringe through a $0.2 \mu \mathrm{m}$ Millipore filter and then diluted with the air drawn through the same filter (ratio: 1 in $5 \mathrm{ml}$ for $20 \%, 2$ in $5 \mathrm{ml}$ for $40 \%$ ). Gas was injected into the AC, under sterile conditions, in the operating theatre. The injection site was the limbus at 3 or 9 o'clock. A 30-gauge half-inch needle was used. The globe was held firmly with a toothed forceps. To minimise iris and lens damage, the bevel was facing the iris plane at the site of the entry. Special care was taken not to inject anterior to Descemet's membrane. ${ }^{11}$ Between 0.15 and $0.2 \mathrm{ml}$ of $\mathrm{SF}_{6}$ was adequate to create a deep $\mathrm{AC}$ in 5 cases. In the other 5 cases some gas escaped into the bleb; they required more gas at the same surgical sitting to maintain a deep AC.

To reduce gas contact with the lens post-operatively, no cycloplegic drop was administered until the gas was completely absorbed. A double pad was applied overnight and the head positioned at $30^{\circ}$. Patients were discharged 1-2 days after the procedure when the gas bubble was fully absorbed or very small. Patients were advised to have minimal activity for 1 week. Topical steroids and antibiotics were prescribed for 2 weeks, after which they were gradually tapered. Three specular microscopies were performed on 6 patients. The first was performed just before injection of the gas, the second after its absorption and the third 3 months later.

\section{RESULTS}

In all cases the $\mathrm{AC}$ remained deep after absorption of the gas. Gas was absorbed in 2-7 days (mean 4.8 days). Six patients had reduced visual acuity after trabeculectomy, 2 of whom (cases 2, 9) improved after the reformation of the AC (Table I). Six patients had cataracts (cases 1, 4, 5, 7, 8, 9), 3 of which developed before and 3 after the reformation (cases 1, 7, 8). Four of these patients (cases 1, 4, 7, 8) had significant reduction of vision. In this group cases 1,4 and 7 underwent cataract surgery and achieved unaided visual acuities of 6/9,6/18 and 6/9 respectively. Case 8 was on the waiting list for cataract surgery. The remaining patients, cases 5 and 9 with mild cataracts, did not have any further surgery (Table II). All cataracts were nuclear sclerotic or

Table II. Ocular findings during and after injection of $\mathrm{SF}_{6}$ into the anterior chamber

\begin{tabular}{|c|c|c|c|c|c|c|}
\hline Patient no. & Final reformation by & Days for gas resorption & Folow-up (years) & Latest ocular finding & Final VA & Final IOP \\
\hline 1 & $\mathrm{SF}_{6} 40 \%$ & 4 & 4.5 & $\begin{array}{l}\text { १Cat.+++ } \\
\text { ECCE+IOL }\end{array}$ & $\begin{array}{l}\mathrm{HM} \\
6 / 9\end{array}$ & $15^{\mathrm{a}}$ \\
\hline 2 & $\mathrm{SF}_{6} 40 \%$ & 6 & 4.5 & - & $6 / 12$ & 18 \\
\hline 3 & $\mathrm{SF}_{6} 40 \%$ & 6 & 2.0 & - & $6 / 18$ & 20 \\
\hline 4 & $\mathrm{SF}_{6} 40 \%$ & 7 & 4.5 & $\begin{array}{l}\text { Cat.+++ } \\
\text { ECCE+IOL }\end{array}$ & $\begin{array}{l}\text { CF } \\
6 / 18\end{array}$ & 17 \\
\hline 5 & $\mathrm{SF}_{6} 20 \%$ & 4 & 0.8 & Cat.++ & $6 / 60$ & $14^{\mathrm{a}}$ \\
\hline 6 & $\mathrm{SF}_{6} 20 \%$ & 2 & 0.5 & Advanced glaucoma & HM & 18 \\
\hline 7 & $\mathrm{SF}_{6} 20 \%+$ sclerostomy & 4 & 3.0 & $\begin{array}{l}\uparrow \text { Cat.+++ } \\
\text { ECCE+IOL }\end{array}$ & $\begin{array}{l}6 / 60 \\
6 / 9\end{array}$ & $17^{\mathrm{a}}$ \\
\hline 8 & $\mathrm{SF}_{6} 20 \%+$ sclerostomy & 5 & 1.0 & $\uparrow$ Cat.++++ & HM & 10 \\
\hline 9 & $\mathrm{SF}_{6} 20 \%$ & 5 & 2.0 & Cat.+ & $6 / 18$ & 18 \\
\hline 10 & $\mathrm{SF}_{6} 20 \%$ & 5 & 0.5 & - & $6 / 6$ & 18 \\
\hline
\end{tabular}

VA, visual acuity; IOP, intraocular pressure; $\uparrow$, progression of cataract; ECCE+IOL, extracapsular cataract extraction + intraocular lens. ${ }^{a}$ With one topical medication. 
cortical; there were no anterior capsular opacities such as usually occur after prolonged gas-lens contact.

All patients had mild corneal stromal oedema before the injection of $\mathrm{SF}_{6}$. This persisted for up to 4 days after the injection. In 4 patients the central stromal oedema increased after the reformation (cases 1, 3, 4, 7). Case 4 had a moderate uveitis with keratic precipitates. All the above conditions recovered in 1 week. A small stromal opacity, away from the visual axis, remained in case 7 , due to mechanical endothelial damage during one of the surgical interventions to reform the AC.

Specular microscopy of corneal endothelial cells showed polymegatism and reduced cell count before the reformation. No deterioration was recorded after absorption of the gas. Specular microscopy of case 5, with 7 days of flat AC, showed a significant reduction in the corneal endothelial cell count $\left(520\right.$ cells $\left./ \mathrm{mm}^{2}\right)$ before the injection of $\mathrm{SF}_{6}$. The cell count did not deteriorate after the injection of gas (Fig. 1). Specular microscopy of case 10 , with 2 days of lenticulocorneal touch, was not as severely affected. The cell count was 2080 cells $/ \mathrm{mm}^{2}$ in the affected eye and 2880 in the normal eye. Three months later this improved to 2240 cells $/ \mathrm{mm}^{2}$ in the affected eye. A similar pattern was noted in the other four specular microscopies.

After absorption of the gas the intraocular pressure remained controlled in all cases. Cases 1, 5 and 7 required one topical antiglaucoma medication, later in their follow-up.

\section{DISCUSSION}

Trabeculectomy, like many other intraocular surgical procedures, can produce hypotony. This is followed by choroidal detachment due to transudation of the fluid into the suprachoroidal space. ${ }^{12,13}$ Injection of gases used in the retinal surgery has been advocated for the reformation of the $\mathrm{AC}$, especially in
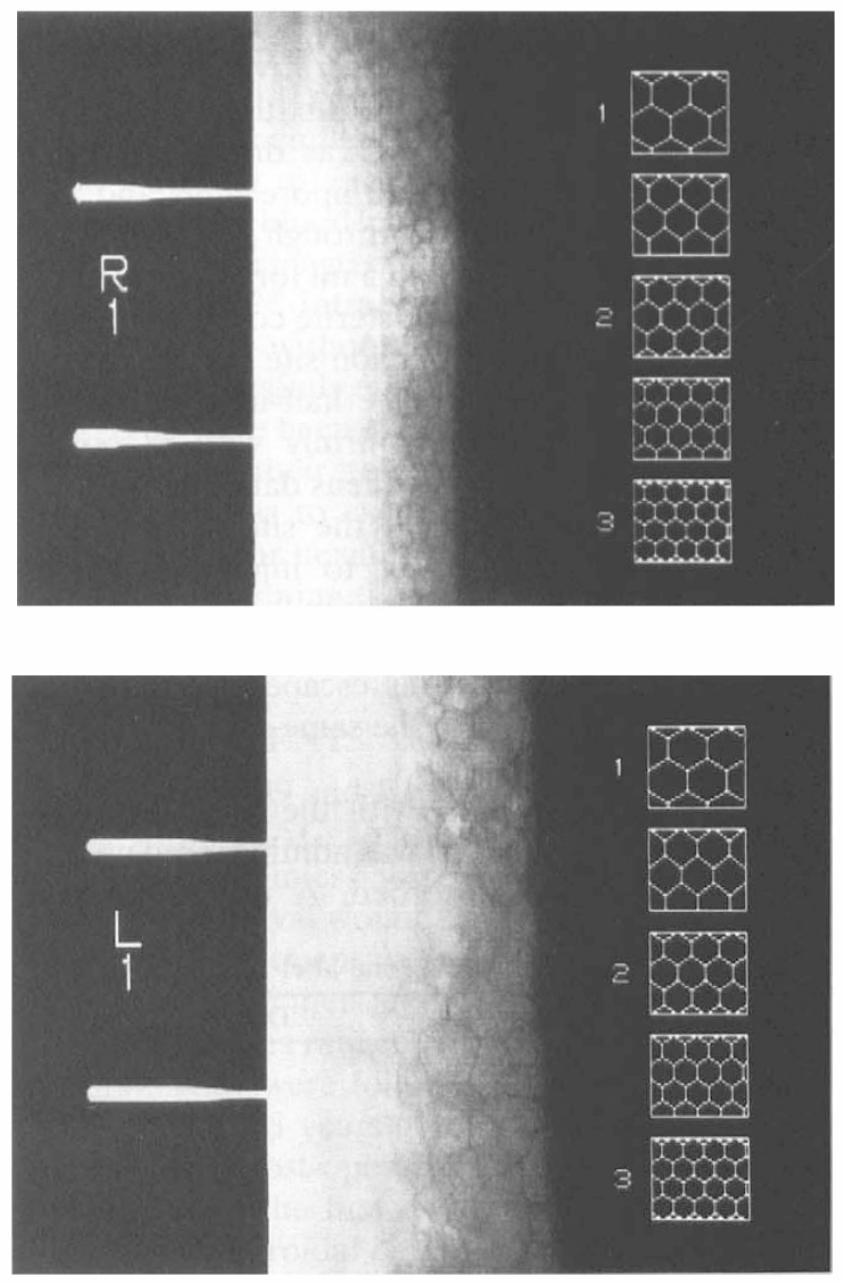

(d)

Fig. 1. Specular microscopy of case 5 with left flat anterior chamber. (a) Endothelial cell count before injection of the gas shows polymegatism and 520 cells $/ \mathrm{mm}^{2}$ in the left eye. (b) Normal endothelial cell count of $2560 \mathrm{cells} / \mathrm{mm}^{2}$ in the right eye. (c) Endothelial cell count of the left eye after absorption of the gas, 5 days later, shows the same reading as before the injection of the gas (600). (d) Endothelial cell count 4 months later shows an increase to $1040 \mathrm{cells} / \mathrm{mm}^{2}$ in the left eye. The right eye count was almost unchanged at 2360 cells $/ \mathrm{mm}^{2}$. 
pseudophakic patients. ${ }^{14} \mathrm{SF}_{6}$ and $\mathrm{C}_{3} \mathrm{~F}_{8}$ are not water soluble. When their intraocular concentration is $50 \%$ or higher, the gas bubble expands as $\mathrm{O}_{2}, \mathrm{~N}_{2}$ and $\mathrm{CO}_{2}$ from the circulation penetrate the $\mathrm{AC}$. The high surface tension of these gases and their high buoyant force seal the fistula and increase the intraocular pressure. Once the intraocular pressure is restored and maintained, transudated fluid will be redirected into the choroidal circulation and the $\mathrm{AC}$ deepens due to the restoration of the vitreous cavity. After a period of equilibrium the bubble is re-absorbed back into the circulation. ${ }^{15}$ When pure gas is used, absorption takes 3-7 days for air, 7-14 days for $\mathrm{SF}_{6}$ and 30-60 days for $\mathrm{C}_{3} \mathrm{~F}_{8} \cdot 1,16,17$

The aim was to use a certain concentration of gas to seal the fistula long enough to restore the $\mathrm{AC}$, but not too long to induce any side-effects. $\mathrm{SF}_{6} 20-40 \%$ has more surface tension than air and is absorbed much faster than $\mathrm{C}_{3} \mathrm{~F}_{8}$. It is absorbed faster in the $\mathrm{AC}$ (2-7 days) than $\mathrm{SF}_{6} 100 \%$ in the vitreous cavity (7-14 days).

Patients in this study had over-filtering fistulas which were not controlled with conservative treatment. In 5 of the cases the AC did not reform after one to four surgical interventions (cases 2, 3, 6, 7, 9). In 2 other cases per-operative injection of air or sodium hyaluronate into the $\mathrm{AC}$ did not prevent a flat AC. ${ }^{18}$ A single injection of $\mathrm{SF}_{6} 20-40 \%$ reformed the $\mathrm{AC}$ in all cases.

Intraocular side-effects of gases have been widely investigated. Recent studies in rabbit eyes have shown corneal stromal oedema and inflammatory cells with a second Descemet's membrane after an injection of air, pure $\mathrm{C}_{3} \mathrm{~F}_{8}$ and pure $\mathrm{SF}_{6}{ }^{19,20} \mathrm{But}$ when $\mathrm{SF}_{6} 50 \%$ and $\mathrm{C}_{3} \mathrm{~F}_{8} 15 \%$ are used only swollen endothelial cells are seen. It is believed that at this concentration neither of the two gases is more toxic than air. ${ }^{1}$

The corneal oedema in cats and rabbits persists as long as $\mathrm{SF}_{6}$ 20-40\% remains in the $\mathrm{AC}$, but resolves 1 week after the absorption of $\mathrm{SF}_{6}$. However, after the absorption of $\mathrm{C}_{3} \mathrm{~F}_{8}$, corneal oedema persists and fibrin deposition on the posterior surface of the endothelial cells forms a membrane. An $\mathrm{SF}_{6} /$ air mixture was therefore considered to be more suitable and was used in this study. ${ }^{21}$ Initially $\mathrm{SF}_{6} 40 \%$ was used, but later in the study it became clear that $\mathrm{SF}_{6}$ $20 \%$ was sufficient to maintain the AC, despite its absorption in less than 4 days. A few cases needed higher volume of the gas during the initial injection as some escaped into the bleb. If further injection of the gas does not deepen the AC adequately, suturing of the scleral flap may be required at the same sitting.

Cataract formation is another complication of a flat $A C{ }^{22}$ Gases produce anterior capsular opacities, especially on the upper half of the lens surface, which can resolve spontaneously. This was not seen in our patients. Acute gas cataract can be avoided by reduction of the gas-lens contact time, using diluted $\mathrm{SF}_{6}$. Cases 1, 7 and later 8 in this study developed cataracts after injection of the gas; however, these were nuclear sclerotic rather than anterior capsular, suggesting that probably gas alone did not contribute to their formation. Three other cases had developed nuclear sclerotic and anterior cortical cataracts immediately after the lenticulocorneal touch.

Gases used in intraocular surgery are not toxic. However, they can create a mechanical barrier between the aqueous humour and corneal endothelial cells and the crystalline lens which can lead to nutritional deprivation of the intraocular tissue. The longer this barrier is in place, the greater the damage. Ironically, a prolonged flat AC damages the cornea and the lens by the same mechanism. In this study a poor endothelial cell count was noted in cases with a longer lens-cornea contact. This did not deteriorate after the injection of $\mathrm{SF}_{6}$. Early absorption of $\mathrm{SF}_{6}$ seems to minimise the nutritional deprivation of tissues in the AC. With the absorption of $\mathrm{SF}_{6} 20 \%$ in 4 days, corneal endothelial cells and the crystalline lens are spared from irreversible damage. ${ }^{23}$

\section{CONCLUSION}

A flat $\mathrm{AC}$ is a serious complication of drainage surgery with a potentially disastrous outcome. Different techniques have been suggested for its management. A single intraocular injection of $\mathrm{SF}_{6}$ $20-40 \%$ was enough to reform the AC of 10 patients in this study, in 5 of whom multiple surgical attempts had been unsuccessful. All patients achieved a reasonable visual acuity and normal intraocular pressure. Twenty per cent $\mathrm{SF}_{6}$ /air mixture is inert and kind to the cornea and, as it is absorbed in less than 4 days, exerts minimal damage to the crystalline lens. A prolonged flat $\mathrm{AC}$ is more traumatic.

We would like to thank Mr Abbas Alaghebandian for his help and support.

This paper was presented at the Annual Meeting of the Royal College of Ophthalmologists, Edinburgh, May 1996.

Key words: Flat anterior chamber, Choroidal detachment, Lenticulocorneal touch, Sulphur hexafluoride.

\section{REFERENCES}

1. Wilson MR, Yoshizumi MO, Lee DA, Martin W. Use of intraocular gas in flat anterior chamber after filtration surgery. Arch Ophthalmol 1988;106:1345.

2. Shin DH. Management of flat anterior chamber with hypotonia after glaucoma surgery. Glaucoma 1982; 4:193-7.

3. Hill RA, Aminlari A, Sassani JW, Michalski M. Use of a symblepharon ring for treatment of over-filtration and leaking blebs after glaucoma filtration surgery. Ophthalmic Surg 1990;21:707-10. 
4. Joiner DW, Liebmann JM, Ritch R. A modification of the use of the glaucoma tamponade shell. Ophthalmic Surg 1989;20:441-2.

5. Hanczy P, Mach AT. Detachment of the choroid after cataract extraction. Klin Oczna 1990;92:229-30.

6. Fourman S. Management of cornea-lens touch after filtering surgery for glaucoma. Ophthalmology 1990; 97:424-8.

7. Franks WA, Hitchings RA. Intraocular gas injection in the treatment of cornea-lens touch and choroidal effusion following fistulising surgery. Ophthalmic Surg 1990;12:831-4.

8. Franks WA, Hitching RA. Injection of perfluoropropane gas to prevent hypotony in eyes undergoing tube implant surgery. Ophthalmology 1990;97:899-903.

9. Schulze F, Schmidtsdorf H. Damage to the corneal endothelium following exposure to sulfur hexafluoride gas. Klin Monatsbl Augenheilkd 1989;194:447-53.

10. Cairns JE. Trabeculectomy: preliminary report of a new method. Am J Ophthalmol 1968;5:673-9.

11. Ostberg A, Tornqvist G. Management of detachment of Descemet's membrane caused by injection of hyaluronic acid. Ophthalmic Surg 1989;20:885-6.

12. Maus M, Katz LJ. Choroidal detachment, flat anterior chamber and hypotony as complications of neodymium:YAG laser cyclophotocoagulation. Ophthalmology 1990;97:69-72.

13. Austin MW, Wishart PK. Reformation of anterior chamber following trabeculectomy. Ophthalmic Surg 1993;24:461-6.
14. Diddie KR, Smith RE. Intraocular gas injection in the pseudophakic patient. Am J Ophthalmol 1980;89: 659-61.

15. Chang S. Intraocular gases. In: Glaser BM, Michels RG, editors. Retina, vol 3. CV Mosby, 1989:245-59.

16. Jacobs PM, Twomey JM, Leaver PK. Behaviour of intraocular gases. Eye 1988;2:660-3.

17. Lincoff $H$, Mardirossian J, Lincoff A, Liggett $P$, Iwamoto J, Jacobiee F. Intravitreal longevity of three perfluorocarbon gases. Arch Ophthalmol 1980;98: 1610-11.

18. Barak A, Alhalel A, Kotas R, Melamed S. The protective effect of early intraoperative injection of viscoelastic material in trabeculectomy. Ophthalmic Surg 1992;23:206-9.

19. Lee DA, Wilson MR, Yoshizumi MO, Hall M. The ocular effects of gases when injected into the anterior chamber of a rabbit eye. Arch Ophthalmol 1991; 109:571-5.

20. Van Horn DL, Edelhauser HF, Aaberg TM, Pederson HJ. In vivo effects of air and sulphur hexafluoride gas on rabbit corneal endothelium. Invest Ophthalmol 1972;11:1028-30.

21. Foulks GN, de Juan E, Hatchell DL, McAdoo T, Hardin J. The effect of perfluoropropane on the cornea in rabbits and cats. Arch Ophthalmol 1987;105:256-9.

22. Shin DH. Trabeculectomy. Int Ophthalmol Clin 1981; 21:47-68.

23. Green K, Cheeks L, Stewart DA, Norman BC. Intraocular gas effects on corneal endothelial permeability. Lens Eye Toxic Res 1992;2:85-91. 